\title{
Mensajería en Wasap y millennials universitarios de Cotopaxi, desafíos para la educación superior de Ecuador
}

Messaging on Wasap and university millennials in Cotopaxi, challenges for higher education in Ecuador

\author{
Volumen 21, Número 1 \\ Enero - Abril \\ pp. 1-28
}

\author{
Máximo Ricardo Gómez-Castells \\ Gina Silvana Venegas Álvarez \\ Nelly Patricia Mena Vargas
}

\section{Citar este documento según modelo APA}

Gómez-Castells, Máximo Ricardo., Venegas Álvarez, Gina Silvana. y Mena Vargas, Nelly Patricia. (2021). Mensajería en Wasap y millennials universitarios de Cotopaxi, desafíos para la educación superior de Ecuador. Revista Actualidades Investigativas en Educación, 21(1), 1-28. Doi. 10.15517/aie.v21i1.44078 


\title{
Mensajería en Wasap y millennials universitarios de Cotopaxi, desafíos para la educación superior de Ecuador
}

Messaging on Wasap and university millennials in Cotopaxi, challenges for higher education in Ecuador

\author{
Máximo Ricardo Gómez-Castells ${ }^{1}$ \\ Gina Silvana Venegas Álvarez ${ }^{2}$ \\ Nelly Patricia Mena Vargas ${ }^{3}$
}

\begin{abstract}
Resumen: Con el objetivo de realizar un acercamiento a la mensajería que el estudiantado revela en Wasap desde la perspectiva del interpretante, y establecer los desafíos que ello representa para la Educación Superior en Ecuador se efectúa la investigación, tal propósito constituye la aportación a una revelación de los efectos producidos en el discurso receptivo cuya lectura transita por la sociolingüística, la filosofía del lenguaje y la pragmática, la convergencia de tales argumentos en el ámbito pedagógico es una posibilidad para la enseñanza desde el discurso digital. En este artículo se ofrece una exploración de la relación potencial entre el uso de la mensajería instantánea y la conformación de interpretantes sobre la base del establecimiento de presupuestos teóricos y metodológicos de la sociolingüística en millennials universitarios de la Carrera de Pedagogía de los Idiomas Nacionales y Extranjeros de la Universidad Técnica de Cotopaxi en Ecuador. La investigación fue de tipo exploratorio y una metodología cualitativa en que se implementó una estrategia de complementariedad de los métodos y técnicas de análisis de documentos, entrevista grupal e individual, encuesta y el análisis hermenéutico del discurso. La muestra fue seleccionada mediante el muestreo no probabilístico, por lo que se conformó un grupo de 10 estudiantes. Los resultados revelaron la serie de interpretantes que generan los millennials universitarios ecuatorianos y las variaciones lingüísticas que tipifican su discurso; información de donde se extrajeron las reglas presentes en la recepción, así como una taxonomía de los interpretantes presentes en la plataforma digital estudiada constitutiva de un modelo de discurso como síntesis de la mensajería instantánea utilizada por los estudiantes. En esta Mensajería se configuran interpretantes que revelan su creatividad significativa, de la cual se derivaron consideraciones acerca de la necesidad de generación de procedimientos de enseñanza basados en la trilogía de Peirce donde el estudiantado forme capacidades cognoscitivas sobre la trascendencia del imaginario lingüístico en el enriquecimiento de la lengua.
\end{abstract}

Palabras clave: educación superior, estudiantes, comunicación, discurso, interpretante.

1 Profesor en la Universidad Técnica de Cotopaxi, Latacunga, Ecuador. Ha realizado la labor de Docente en Cuba, México y Ecuador. Doctor en Ciencias Sociológicas en la Universidad de Oriente, Santiago, Cuba. Dirección electrónica: maximogom457@gmail.com Orcid https:// orcid.org/0000-0002-4685-3477

2 Docente Titular de la Universidad Técnica de Cotopaxi, Latacunga, Ecuador. Docente de la enseñanza de inglés. Doctorante en la Universidad Nacional de Rosario, Rosario,

Argentina. Dirección electrónica: gina.venegas@utc.edu.ec Orcid: https://orcid.org/0000-0003-3263-6225

3 Docente Titular y Vicedecana de la Facultad de Ciencias Humanas y Educación de la Universidad Técnica de Cotopaxi, Latacunga, Ecuador. Magister en Docencia Universitaria y Administración Educativa de la Universidad Tecnología Indoamérica del Ecuador, Quito, Ecuador. Direcciónｅlectrónica: Nelly.mena@utc.edu.ec Orcid: https://orcid.org/0000-0002-9218-1333

Artículo recibido: 26 de junio, 2020

Enviado a corrección: 2 de setiembre, 2020

Aprobado: 19 de octubre, 2020

Los contenidos de este artículo están bajo una licencia Creative Commons 


\begin{abstract}
In order to make an approach to the messaging that the student body reveals in Wasap from the perspective of the interpreter and to establish the challenges that this represents for Higher Education in Ecuador, the investigation is carried out, such purpose constitutes the contribution to a revelation of the effects produced in the receptive discourse whose reading passes through sociolinguistics, language philosophy and pragmatics, the convergence of such arguments in the pedagogical field is a possibility for teaching from digital discourse. This article offers an exploration of the potential relationship between the use of instant messaging and the formation of interpreters based on the establishment of theoretical and methodological assumptions of sociolinguistics in university millennials of the National and Foreign Languages Pedagogy Career from the Technical University of Cotopaxi in Ecuador. The research was of an exploratory type and a qualitative methodology in which a strategy of complementarity of the methods and techniques of document analysis, group and individual interview, survey and the hermeneutical analysis of discourse was implemented. The sample was selected through non-probability sampling, being made up of 10 students. The results revealed the series of interpreters that Ecuadorian university millennials generate and the linguistic variations that typify their discourse; information from where the rules present in the reception were extracted, as well as a taxonomy of the interpreters present in the digital platform studied constituting a model of discourse as a synthesis of the instant messaging used by the students. Messaging where interpreters are configured that reveal their significant creativity, from which considerations were derived about the need to generate teaching procedures based on Peirce's trilogy where the student body forms cognitive capacities on the transcendence of the linguistic imaginary in the enrichment of the language.
\end{abstract}

Key Words: higher education, students, communication, interpreters, discourse.

\title{
1. Introducción
}

El impacto que ha producido internet en el siglo XX puede sintetizarse en los efectos que representa la expansión de la tecnología móvil, así como el uso de Wasap ${ }^{4}$; esta última como plataforma digital que aplica la mensajería instantánea. Esa herramienta plantea una utilidad significativa para acortar distancias, facilitar el acceso a la información y la comunicación desde cualquier lugar e instante de la vida de las personas. Ante dicha realidad, las ciencias de la educación y las Instituciones de Educación Superior realizan análisis y evalúan impactos de los entornos virtuales en los procesos formativos; sin embargo, dichos estudios sobre la mensajería instantánea, no son frecuentes desde una perspectiva sociolingüística ya que solo se centran en las ventajas didácticas e impacto psicopedagógico (Padrón, 2013 y Suárez, 2018a).

La perspectiva sociolingüística produce en el estudiantado, en primer lugar, cultura contextualizada y profesionalizante para la explicación científica de las transformaciones que ocurren en la comunicación, particularmente en la enseñanza de segunda lengua y, en segundo lugar, intencionalidad formativa para el análisis de la mensajería instantánea en Wasap. Suárez (2018) y Trejos (2018) caracterizan la mensajería instantánea por la efectividad y fluidez en la comunicación, el intercambio de información desde cualquier lugar y momento, la posibilidad de comunicación por texto, vídeo, fotografía y audio como un lenguaje asociado

\footnotetext{
${ }^{4}$ La versión wasap refiere la Real Academia de la Lengua Española es preferible a la forma WhatsApp según menciona el Director honorario Víctor García de la Concha (citado por Morales, 2018).
} 
al moderno lenguaje natural. La interdependencia de la perspectiva sociolingüística y los rasgos de la mensajería instantánea sustentan la estrategia formativa para el desarrollo de la competencia oral en un segundo idioma (Andújar-Vaca y Cruz-Martínez, 2017) y la posibilidad de construir conocimiento grupal (Padrón, 2013).

No obstante, Fondevila, Cabreras, Mir, Del Olmo y Pesqueira (2014) advirtieron que el uso de estas aplicaciones produce estrés y ansiedad por la necesidad de recibir respuesta inmediata a los mensajes. Estos autores, también señalaron que el tiempo conectado en internet afecta al aprendizaje del estudiantado, hechos que pueden ocasionar la aparición de déficit de atención por hiperactividad. El análisis sociolingüístico de la aplicación Wasap puede influir a favor de la práctica discursiva del estudiantado que dedica gran parte del tiempo a la mensajería instantánea.

En paralelo, algunas investigaciones distinguen a los millennials universitarios 0 generación $\mathrm{Y}$, como nativos digitales que utilizan eficientemente las tecnologías de la información, lo que los convierte en autodidácticas (Olivares y González, 2016). Esta generación joven constituye un nivel dentro de la estructura social ecuatoriana, al ser reconocidos, según la Ley de la Juventud (2001), como los comprendidos entre 18 y 29 años. Recuérdese que cada país tiene una escala de edades diferentes para las personas jóvenes en atención a su desarrollo socioeconómico. Ecuador en el 2006 tenía una tasa de obtención de título universitario de un $8 \%$, situación más grave en los estratos juveniles étnicos indígenas y afroecuatorianos con un $8,5 \%$ y $13,2 \%$.

Refiriéndose a los millennials Jay señala que los millennials "se reconocen como los nacidos entre las décadas del 80 al 2000 cuya relación con las TIC transcurre de forma más espontánea y natural" (2006, p. 4), esto explica el por qué asimilan el cambio de paradigma que representa la irrupción de dichas tecnologías en las sociedades (Gómez-Castells, Venegas y Mena, 2020, p. 30). A la vez, tienen una actitud positiva respecto al Consumo Social (Peñalosa y López, 2016). Al respecto, Popescu, Popa y Cotet (2019) subrayaron la necesidad de conocer sus hábitos de estudio y preferencias como grupo, por ser la población más importante de estudiantes universitarios (Silvestre y Cruz, 2016). En consonancia con su dimensión como comunidad universitaria Gómez-Castells et al. (2020) han precisado:

La estrecha relación que tienen los millennials con las TIC condiciona no solo la elección de las vías de comunicación entre ellos, sino también los discursos que se articulan en el interior del grupo social. Por supuesto, que les ha tocado desarrollar prácticas discursivas propias, en la articulación de la comunicación a través de las plataformas y 
redes sociales. Este es un tema de sumo interés para los sociolingüistas, que debe ser estudiado en profundidad, apelando a todas las herramientas conceptuales y metodológicas que dicha disciplina social brinda. (p. 33)

Venegas-Álvarez y Proaño-Rodríguez (2019) sobre un análisis sociolingüístico de las prácticas discursivas a través de Wasap en millennials de la carrera de Pedagogía de Idioma Nacionales y Extranjeros, de la Universidad Técnica de Cotopaxi y el impacto del uso de una jerga como forma de comunicación, determinaron que las variantes lingüísticas más frecuentes al interior del grupo se muestran como: abreviación de palabras eliminando letras, la sustitución de palabras completas por una letra y la utilización de palabras de un idioma extranjero. Ello puede producir innovaciones sociolingüísticas en la emisión y recepción discursiva al fomentar variantes lingüísticas significativas en millennials universitarios.

En el análisis de varios factores pragmáticos que determinan las propiedades lingüísticas y textuales de los discursos, Llamas (2005), distingue al discurso oral del discurso escrito sobre la base del soporte físico del lenguaje, las propiedades lingüísticas (léxicas, morfosintácticas, textuales) y factores contextuales que intervienen en el proceso comunicativo. Esta autora afirmó que ya no encontramos dos tipos de discursos, el oral y el escrito según el canal por el cual se transmiten, pues un mensaje de texto en Wasap puede tener un carácter coloquial y presentar rasgos propios de lo oral; tal es el caso, de la unión de la fraseología y la lingüística de variedades usado por cualquier hablante/emisor en cualquier momento, contexto, tipo de texto u otro (Sinner y Tabares, 2016).

La teoría pragmática se centra en la realización del lenguaje, allí ilustra una polémica de la producción discursiva con la recepción del texto; a pesar de ello, se localiza una preeminencia hacia el análisis del contexto productivo representado por el emisor, mientras que el análisis de la recepción del discurso se limita a la explicación del modo en que son configurados los discursos, hecho que obvia el estudio de los comportamientos que muestran las personas cuando realizan sus reacciones significativas lo cual ha soslayado a su vez la revelación de las comprensiones que provocan las apelaciones del emisor. Ese déficit determina el estudio que se presenta y su resultado orientado por la interrogante ¿Qué interpretantes sociolingüísticos asumen los millennials universitarios de Cotopaxi en sus comportamientos discursivos sustentados en la teoría sociolingüística? Interrogante que puede responderse desde la idea que los interpretantes son en el ámbito significativo una 
semiosfera que crean los sujetos desde una dimensión interpretativa relacional, cual elemento de una perspectiva triádica, en su discurso al decodificar un texto.

En tal comportamiento discursivo se producen apelaciones con valor identificativo en los géneros, donde la alternativa es libre, así es en los foros electrónicos (Rigatuso, 2014) de las plataformas digitales. De los planos del lenguaje se ha seleccionado el pragmático-discursivo ya que constituye, según Rigatuso, tema implicado en los estudios sobre fórmulas de tratamiento, aspectos definitorios para la lógica funcional de la apelación, en especial, las pautas de uso.

Villalba y Kern (2017) definen la apelación como formas de tratamiento configuradas como partículas nominales o pronominales y mediante fórmulas apelativas convencionalizadas para movilizar al destinatario. Las fórmulas apelativas convencionalizadas revelan escasa presencia en la bibliografía, ya que en las pronominales se localizan mayor número de trabajos (Blas, 1994; Calderón y Medina, 2010; Carricaburro, 1997; Fontanella de Weinberg, 1999), entre los de relevancia.

Para el caso, se realiza una práctica de investigación a los usos hechos en los servicios y herramientas de mensajería instantánea Wasap por los sujetos seleccionados, en aras de obtener un análisis del discurso producido por las personas investigadas, que el estudio denomina como interpretantes, presentes en los mensajes del estudiantado de la Carrera de Pedagogía de los idiomas Nacionales y Extranjeros de la Universidad Técnica de Cotopaxi. Esta población fue escogida con el objetivo de facilitar estudiar las innovaciones léxicas que manifiestan dichos receptores en su vida cotidiana; así como, los determinantes sociolingüísticos que se aprecian en su recepción discursiva.

\section{Referente teórico}

Explicar los efectos que revela el emisor, identificados como interpretantes, es una aportación poco desarrollada y menos explicada, en un ámbito donde son identificables las dimensiones que la función apelativa alcanza como producto de la recepción del discurso, un hecho que varios autores subrayan (Bühler, 1934; Jakobson, 1963; Halliday, 1978). La obviedad de tal perspectiva provoca un nivel de análisis del discurso en clases, basado en conocimientos elementales que son reiterados por el profesorado de lengua; tal reiteración estanca el conocimiento científico de la población estudiantil quien no desarrolla entonces su capacidad de reflexión. Por otro lado, se desconoce que las ciencias del lenguaje poseen otros campos que realizan aportes significativos a la explicación de los argumentos que emplean 
hablantes y receptores; como reacciones producidas, fruto de las apelaciones que contienen los textos interpretados por dichos receptores.

Las apelaciones son fórmulas de tratamiento con fuerza ilocutiva presentes en el discurso con variedad funcional; la variedad se ha clasificado como funciones que marcan mediante recursos lingüísticos las relaciones interpersonales y la identidad, ya sea singular o colectiva, para organizar el texto. Su funcionalidad es de índole sociolingüística por lo cual revelan contextos socioculturales en los propósitos discursivos de los productores y receptores de discursos. Los receptores pueden generar efectos que indican la eficacia de las apelaciones. Entre las funciones pertinentes con el estudio se pueden referir la valorizadora y la retórica; la primera establece vínculos con el subrayado enaltecedor de los participantes en aras de preservación de relaciones interpersonales; por su lado, la retórica opera con la capacidad para controlar el flujo del habla y ordenar las ideas en el discurso (Villalba y Kern, 2017). Al interior de dichas formas de tratamiento, subyacen los interpretantes, cual disposición de variantes pragmático-discursivas.

Epistemológicamente el interpretante fue definido por Charles Peirce en su teoría semiótica marcada por una perspectiva filosófica; para este autor, existe una relación triádica: del signo o representamen, de ese con su objeto y del emisor o receptor con el significado; es triádica porque se sustenta en tres dimensiones filosóficas: primeridad, segundidad y terceridad; esta última, tiene un término en relación: el interpretante. Dan cuenta, dichas categorías, de la experiencia del ser. ¿Qué tipo de experiencia refleja el interpretante? La referida a la mediación que establece un signo con el objeto que lo determina, por tanto, es un mediador que según Nicole Everaert-Desmedt pertenece "al dominio de las reglas y solo puede apreciarse en su aplicación" (2004, p. 33). De esta manera, sintetiza entonces el pensamiento, el lenguaje, la representación y el proceso de la semiosis; es decir, la vida del signo que facilita la comunicación social.

Peirce aclara que entre el representamen y el interpretante existe una dialéctica relativa ya que el primero genera la semiosis que ilustra el interpretante y este a su vez se transforma en representamen generatriz de otro interpretante, dando lugar a la serie de interpretantes. Para este autor, se produce una serie de interpretantes como característica de una semiosis infinita que resume Everaert con la idea: "proceso de pensamiento que es siempre incompleto y que siempre ha comenzado con anterioridad" (2004, p. 5).

En el orden metodológico se manifiesta una brecha en cuanto al dominio de estos procedimientos de estudio en la enseñanza que puede hacer más atractiva la dinámica áulica; 
fundamentalmente, porque en la educación superior se pueden identificar las categorías que explican fenómenos simbólicos y sociales, presentes en la comunicación: fundamentos del signo como representamen o símbolo en relación, del objeto cual referente dinámico y del significado como experiencia del ser o interpretante. Esa dimensión triádica puede proponerse como desafío a los estudiantes, la cual podrá ser explicada desde los efectos de las apelaciones que promueven las formas de tratamiento, en lugar de utilizar solamente los hechos registrados en las gramáticas o diccionarios.

Los estudiosos referenciados representan una colocación creciente de la trascendencia que posee la recepción cuando se posiciona el estudio en las funciones señalativa o apelativa de Bühler (1934); autor que establece un campo mostrativo y otro simbólico, cual manera de ilustrar el comportamiento del emisor y su realización por el receptor. Una visión que identifica al receptor en una supuesta conducta pasiva o interpretativa (Gómez et al., 2019). Una indefinición que condujo a la ciencia del lenguaje y su filosofía a producir un modo de evitar tal postura ambigua; intención que se logró con la denominada función conativa de Jakobson (1963) quien sitúa en la decisión comprensiva del destinatario la realización del acto de habla, mediante la precisión de un actor o actriz, buscando influir en el pensamiento o en las acciones del receptor. Una visión donde sigue presente la postura pasiva, aunque las conductas emergen como predeterminadas e instrumentales al explicarse cual producto del modo imperativo.

El receptor en esa condición se siente en una doble postura que Halliday (1978) denominó metafunciones, ya que asume una conciencia y, a la vez, es objeto de las condiciones de la dinámica social que estructuran el proceso semántico en el texto; dinámica contentiva de una interacción lingüística entre el receptor y los significados a elegir, los cuales son determinados por los atributos culturales del actor o actriz involucrada. Esta idea en los efectos constituye un giro a la concepción estructural de los estudios del lenguaje ya que retribuye la trascendencia de la dimensión sociocultural en los actos discursivos. Esa dimensión es una condición pragmática con la finalidad de influenciar mediante la persuasión y la convicción que, según Perelman, Sevilla y Olbrecthjs-Tyteca (1989), son maneras en que los sujetos obran en un sentido o a propósito de sus ideas que puede modificar el sentido propuesto.

En ese espacio emergen los aportes de Peirce (1977) con la perspectiva tríadica que incorpora una dimensión interpretativa relacional en el análisis del lenguaje. El signo, entonces evaluado desde la transdisciplinariedad, que Umberto Eco refiere cuando la existencia de una 
relación de la semiótica con diferentes disciplinas científicas, entre las cuales se encuentran la filosofía del lenguaje y la psicología señala: "...no se puede negar que Peirce haya concebido en alguna ocasión al interpretante como un fenómeno psicológico" (1991, p. 33); la colocación de un interfaz semiótico-psicológico revela que el interpretante es un fenómeno objetivo advertido por Peirce (1977).

En relación con ello, Eco (1991) advirtió: “La triada de Peirce puede también aplicarse a fenómenos que no tengan emisor humano aun cuando tengan un destinatario humano" (p. 33). Esa autonomía posee el significado y demuestra como el uso del signo va generando una realidad que exige ser estudiada como resultado de la conciencia social. Reflexión que se relaciona con la definición por la ciencia del concepto de texto que ha desarrollado la lingüística textual al definirlo como "unidades de dimensiones variables caracterizadas por una autonomía total de la que carecen las unidades de niveles distintos (palabra, frase, oración) con dependencia de unidades jerárquicas superiores" (Guerrero, 1995, p. 443).

El interpretante contiene esa autonomía total porque está determinado por el significado que Umberto Eco identificó como "unidades culturales que representan una persona, un lugar, una cosa, un sentimiento, una situación, una fantasía, una alucinación, una esperanza o una idea" (Eco, 1999, p. 62), para ese autor, constituyen soportes de un desarrollo connotativo o reacciones semánticas capaces de producir reacciones de comportamiento donde el desarrollo y las reacciones constituyen interpretantes.

La concepción del interpretante tiene su fundamento en lo que la Sociolingüística y la Pragmática lingüística han definido como objeto de estudio, la primera el uso de la lengua desde la estructura social, mientras que la segunda se ancla en el uso concreto de la lengua y en su aspecto comunicativo, se sostiene entonces, en la dimensión histórica y social de la producción de sentido. De esta manera y, partiendo del fundamento de la concepción del interpretante anteriormente mencionado, se conceptualizó al comportamiento discursivo como "la categoría de fuerzas ilocutivas" (Schlieben-Lange, 1975, p. 57); es decir, como efecto social que genera el interpretante.

En cuanto al efecto social, es importante describir como el discurso es social por naturaleza:

El discurso es un posicionamiento que contiene a la vez una perspectiva psicologista porque explica que las representaciones psicoanalíticas son un resultado de la interacción social, es decir que en el diálogo los sujetos imaginan al receptor en condiciones comunicativas armónicas; de tales argumentos emergen fundamentos 
semióticos que el Círculo de Bajtin produjera en los cuales se destaca la idea de que el texto no existe, solo la interpretación. (Volóshinov, 2009, p. 27)

Esto significa que el llamado dialogismo alude a una estructura enunciativa del texto donde las personas establecen relaciones a propósito de la semiosis del signo. Al respecto, Volóshinov (2009) subrayó: "los individuos en el contacto con la realidad reciben una "refracción", un ámbito refractante que conforma los sentidos de la realidad de acuerdo a su ideología de clase" (p. 21). Resulta así, un antecedente que retoma Peirce (1977) en el interpretante. La postura de Volóshinov, revela un reduccionismo al situar la refracción solo en el ámbito del texto político; pero, es un valioso develamiento porque permitió adicionar las "reacciones semánticas y un desarrollo connotativo que amplían la idea de la refracción" (Eco, 1999, p. 27).

El énfasis en la existencia de un contexto social con un rol en el discurso constituye un constructor de significado, que la filosofía sintetiza cual comprensión de la realidad objetiva mediada por factores socioculturales presentes en la comunicación y que, de acuerdo con Acero, Bustos y Quesada (2001), como posicionamiento representa "un cambio metodológico en la filosofía, que se explica mediante el hecho de tratar los problemas ontológicos desde el examen de la manera en que los mismos se anclan en el lenguaje natural" (p. 15). Por esa razón, el autor al hacer alusión al lenguaje natural se ubica en las intencionalidades de la preferencia; mientras que estudiar el lenguaje desde dicho cambio, es una lectura al discurso como vehículo observable de los pensamientos (Frápolli y Romero, 2007, p. 17).

Esa concepción favorece el análisis de la lengua a partir de los factores contextuales relacionados con el empleo de los signos en el ámbito del objeto de estudio de la pragmática. Al respecto, Peirce (1977) afirmó: "la Terceridad es el nexo triádico existente entre un signo, su objeto y el pensamiento interpretante, él mismo un signo, considerado como constitutivo del modo de ser signo" (p. 41). La precisión de que el interpretante es un pensamiento que asume forma sígnica revela a su vez la relación con el intérprete y las intérpretes quienes asumen un rol comprensivo y, por tanto, inferencial.

Tal comportamiento discursivo define a la gramática de recepción frente a las gramáticas referenciales que tienen un carácter general (Llamas, 2005) porque están construidas por fines más explicativos que descriptivos (Charaudeau, 2009). Llamas (2005) atribuyó, sin embargo, al interpretante un carácter normativo y cita a Castañares (1992) para explicarlo: "la concepción peirceana del interpretante como efecto producido por un signo y al mismo tiempo 
como regla de interpretación, permite explicar cómo es posible conciliar lo general (regla) con lo particular (uso)" (p. 137). Conclusión que favorece apreciar al interpretante desde la Gramática y desde la Pragmática, hecho que Llamas (2005) observó como dos tipos de análisis de la realidad del lenguaje, aunque distintas porque al ubicarse en el interpretante Peirce (1977) lo hace en una recepción creativa: "el interpretante remite hacia atrás al signo y hacia delante él mismo, puesto que es un signo que produce un interpretante nuevo" (p. 33).

Lo anterior, puede ser estudiado mediante reglas de interpretación. La novedad de la gramática de recepción es que resulta una referencia de las posibilidades inferenciales del intérprete que se sintetizan del modo siguiente:

- Reconocimiento de la intención del locutor,

- Principios de comprensión sustentados en conocimiento no literal,

- Apelación a elementos deícticos y al conocimiento del uso del sistema,

- Entendimiento mediante las macroestructuras de significación,

- Nexos: tiempo, razones, efectos y oposición.

Las reglas presentadas argumentan los comportamientos que asumen los receptores del discurso para realizar su consumo del sentido. Proceso de apropiación de significados que no solo es de pensamiento, ya que produce cambios y variaciones en la forma que sufre una lengua al ser empleada. Los tipos de variaciones que la lingüística había reconocido eran: diatópica, determinada por factores geográficos; diacrónica por históricos y, diastrática por elementos de tipo sociocultural. (Venegas-Álvarez y Proaño-Rodríguez, 2019).

\subsection{Hegemonía de los préstamos anglosajones en Wasap}

Casi todos los idiomas reciben su influencia por el peso que tiene tanto en los medios de comunicación como en los adelantos tecnológicos. El español hispanoamericano y el de los residentes en distintas partes del ámbito anglosajón se nutren de cruces. La influencia hace que se produzcan muchas copias semánticas relacionadas con la informática, a pesar de que tienen correspondencias significativas en el español; es notorio el empleo de directorio, que proviene de "directory" cuando existe guía. Entre los más frecuentes se pueden citar: "staff" por equipo; "full time" y "brainstorming". Ello revela que esa influencia no se limita a términos concretos, más bien son el resultado de creaciones desde raíces anglosajonas.

Refiriéndose a los préstamos léxicos Moreno de Alba planteó: "son el fenómeno más socorrido asociado al contacto lingüístico" (1992, p. 196), el mismo que se produce necesariamente a raíz del contacto intercultural, o sea no hay trascendencia lingüística sin 
trascendencia cultural. Por lo tanto, la necesidad de nombrar nuevos objetos o conceptos hace que se incorporen al castellano nuevas palabras procedentes, en la mayoría de la lengua inglesa; son los anglicismos ante los cuales existen dos soluciones: la hispanización o el simple empleo del extranjerismo. El spanglish es el mestizaje del inglés y el español. Se pueden distinguir tres clases: formal, informal y ciberspanglish.

El fenómeno de los anglicismos es muy amplio en español y se puede estudiar desde diversas perspectivas. En su mayoría, el énfasis de los estudios ha recaído en los anglicismos léxicos y se tiende simplemente a clasificar tales voces. Entre los investigadores más aportativos se encuentra Labov (1983) quien expresó: "la sociolingüística tiene entre sus objetivos descubrir el orden que puede haber en la variación y el cambio lingüístico" (p. 209). Ese objetivo, dicha ciencia lo cumple mediante la cuantificación, en razón que los métodos cualitativos para el análisis resultan paralelos. La teoría del interpretante tiene como fin el estudio de las diferencias lingüísticas producidas por los atributos sociales (clase, edad, sexo), contextuales y geográficas; esos atributos determinan las variaciones en el lenguaje de los estudiantes; es decir, las series de interpretantes.

Tales variaciones son quienes han determinado la sociología variacionista donde Moreno (2005, pp. 140,142) identificó la heterogeneidad como cualidad fundamental de los estudios sociolingüísticos ya que se ocupa del lenguaje cotidiano, mediante observaciones sistemáticas y asistemáticas y la adecuada comprensión de las reglas de variación. Este enfoque Labov (1983) lo había asumido para perfeccionar la dialectología y el generativismo vinculados al contexto social. En ese contexto se inserta Wasap con su comunicación digital, instantánea, veloz y estableciendo mensajes breves; tales textos se distancian de los modelos gráficos tradicionales.

\section{Metodología}

\subsection{Enfoque}

Esta investigación fue de tipo exploratorio, donde se utilizó una metodología cualitativa en la cual se respetó el proceso inductivo que permitió profundizar en el tema de investigación.

La estrategia metodológica que asume el estudio se sustentó en la complementariedad de métodos, pues utiliza etapas y métodos: revisión de documentos secundarios, una entrevista individual, entrevista grupal, descripción e interpretación del texto y análisis hermenéutico del discurso (Strauss y Corbin, 2002); la cual permitió generar una comprensión del interpretante en la plataforma virtual Wasap. 


\subsection{Unidades de análisis}

La complejidad del estudio sociolingüístico está dada por las comprensiones hermenéuticas. Se asumió el muestreo no probabilístico en el cual, según Creswell (2005) citado en Hernández, Fernández y Baptista (2014):

la unidad de análisis es el grupo (lo que expresa y construye), una especie de entrevistas grupales, las cuales consisten en reuniones de grupos pequeños o medianos (tres a 10 personas), en las cuales los participantes conversan a profundidad en torno a uno o varios temas. (p. 409)

Quedando conformado por 10 educandos que manifestaron en la entrevista individual su consentimiento a participar en la investigación. La distribución por edades de la muestra es de 18 a 25 años. (Tabla 1).

Tabla 1

Universidad de Cotopaxi, Ecuador: Distribución de estudiantes de la muestra por años de edad, segundo semestre 2019. (valores nominales)

\begin{tabular}{lccccc}
\hline $\begin{array}{l}\text { Número de } \\
\text { Estudiantes }\end{array}$ & $\begin{array}{c}\text { Años de } \\
\text { Edad }\end{array}$ & $\begin{array}{c}\text { Edad } \\
\text { Mínima }\end{array}$ & $\begin{array}{c}\text { Edad } \\
\text { Máxima }\end{array}$ & $\begin{array}{c}\text { Mediana } \\
\text { (Mdn) }\end{array}$ & $\begin{array}{c}\text { Promedio } \\
\text { (M) }\end{array}$ \\
\hline Estudiante-1 & 25 & & & & \\
Estudiante-2 & 24 & & & & \\
Estudiante-3 & 23 & & & & \\
Estudiante-4 & 22 & & & & \\
Estudiante-5 & 21 & & & & \\
Estudiante-6 & 20 & & & & \\
Estudiante-7 & 20 & & & & \\
Estudiante-8 & 19 & & & & \\
Estudiante-9 & 18 & & & & \\
Estudiante-10 & 18 & & & & \\
\hline
\end{tabular}

Fuente: Elaboración propia, con información de la entrevista grupal realizada al estudiantado de la muestra, 2020.

Como aspecto adicional para caracterizar la muestra, se incluyó la presencia de mujeres (Figura 1). Algo más de la mitad de la muestra son hombres. Las unidades de análisis determinadas fueron las unidades culturales que utilizaron en sus discursos, tanto en entrevistas como encuestas, vistas como serie de interpretantes, jerarquizados desde la estabilidad en el uso como signo de confianza del código lingüístico. 


\section{Figura 1}

Universidad de Cotopaxi, Ecuador: Distribución porcentual del estudiantado de la muestra según sexo, segundo semestre 2019.

(porcentaje)

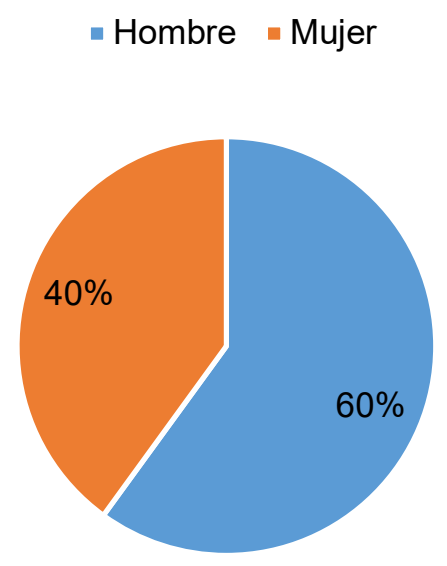

Fuente: Elaboración propia, con información de la de la entrevista grupal realizada al estudiantado de la muestra, 2020.

Sobre la zona geográfica de procedencia, puede referirse que el 100\% de los miembros de la muestra residen en zonas urbanas de la provincia de Cotopaxi, Ecuador y estudian la carrera de inglés. Finalmente, el 100\% afirmaron utilizar cualquier tipo de práctica de servicios o herramientas de mensajería instantánea en la plataforma Wasap. Tales categorías representan fenómenos simbólicos y sociales como argumentos comunicativos que permiten construir la semiosis infinita mediante la relación representamen-interpretante como experiencia de la persona.

El estudiantado participante fue consultado desde la perspectiva de la asignatura que cursan: Sociolingüística y con la propuesta aceptada de ser colaboradores de la investigación que desarrolla la Carrera durante los años 2019-2020, periodo más general del cual se extrajo el segundo semestre del 2019 para presentar los resultados parciales en el artículo.

\subsection{Técnicas de recolección}

La estrategia de la investigación se configuró mediante la integración de perspectivas epistemológicas y metodológicas a través de las siguientes etapas:

En una primera etapa la revisión de documentos secundarios (publicaciones científicas y documentos legales) para la construcción del marco teórico referencial del tema.

En una segunda etapa, se realizó la entrevista individual para obtener la anuencia de los educandos que aceptaban participar en la investigación. 
La tercera etapa se desarrolló mediante una entrevista grupal, con una guía semiestructurada a los 10 miembros de la muestra, que conformaron el grupo de enfoque (Hernández et al., 2014, p. 409), con el propósito de recopilar datos primarios sobre el conocimiento sociolingüístico, cuyo discurso oral, permitió definir los temas a incluir en la encuesta, así como confirmar sus conocimientos sociolingüístico y tecnológico.

La cuarta etapa consistió en la aplicación de la encuesta con un cuestionario semiestructurado cuyas respuestas generaron un texto que fue objeto de un análisis hermenéutico (Strauss y Corbin, 2002). Esta técnica de estudios permitió identificar la apropiación de las nociones significativas desde las experiencias gnoseológicas del ser y, que constituyeron los interpretantes del receptor.

\subsection{Procesamiento de análisis}

El análisis de las respuestas constituyó un modo de descripción e interpretación de las apelaciones en el discurso de la recepción, reacciones que conforman las respuestas de la encuesta aplicada. Tal estudio permitió generar una comprensión del interpretante en la plataforma virtual Wasap y con ello revelar la importancia de la concepción tríadica para caracterizar los interpretantes. El análisis de los aspectos sociolingüísticos que se relacionan a continuación incluye los criterios y rúbricas correspondientes:

a) modos de representación de los interpretantes: un criterio fue las variantes lingüísticas pertinentes, considerando las ideas, sentimientos y cosas inherentes al signo como máxima expresión de este aspecto. Otro criterio, lo fue las huellas del contexto, atendiendo al grado de efectividad de lo social en el discurso de los actores implicados. De modo que, si se manifiesta la máxima expresión en ambos criterios se considera que presenta modos de representación de los interpretantes de manera precisa, si solo se manifiesta un criterio entonces es impreciso.

b) frecuencia de uso de la mediación activa de Wasap: un criterio fue el proceso dinámico, considerando el ritmo de las variantes lingüísticas como expresión de este aspecto. Otro criterio, lo fue las competencias lingüísticas, atendiendo a la amplitud de dominio gramatical desde los atributos socioculturales. De modo que, si se manifiesta la máxima expresión en ambos criterios se considera que presenta una frecuencia de uso significativa, si solo se presenta un criterio, parcialmente significativa.

c) fuentes del lenguaje simbólico y la originalidad: el criterio fue las nuevas relaciones con fenómenos emergentes de la globalidad, considerando las unidades culturales 
explicativas de los usos del lenguaje y la satisfacción de las necesidades comunicativas de los actores en la actualidad. De modo que, si se manifiesta la máxima expresión en este criterio se valora de enriquecedora y creativa, lo contrario será empobrecedora y formal.

d) capacidad del signo: el criterio fue el alejamiento de las grafías y del lenguaje escrito por el empleo de las imágenes, considerando que las reiteradas apelaciones a las emociones supera las razones. De modo que, si se manifiesta la máxima expresión en este criterio se valora la comunicación de ideas del signo de modo inteligible y socializador.

e) desarrollo del pensamiento mediante Wasap: el criterio fue las nuevas lógicas y configuraciones del significado y el significante, considerando que se construyen los textos empleando nuevas formas significante: voz, texto, imagen y sonido para expresar nuevos significados. De modo que, si se manifiesta la máxima expresión en este criterio se valora la existencia de un pensamiento desarrollador.

\section{Resultados}

A continuación, se muestran los resultados, son obviados los correspondientes a la entrevista individual, porque ya fueron presentados en el numeral 3.2.

\subsection{Resultados de la entrevista grupal:}

La entrevista grupal aportó un corpus de temas que resultaron trascendentes para el estudio debido a que se instalaron en la perspectiva estructural y significativa del signo; los comentarios expresados por los educandos se sintetizaron en apreciar en Wasap:

- su incidencia

- mediación activa

- el repertorio de significados

- la capacidad del signo y del objeto

- el desarrollo del pensamiento

- cambios y transformaciones lingüísticas.

Dichos temas permitieron configurar orientaciones léxicas que fueron definidas cual uso de signos con originales sentidos, presencia de códigos para mediación temporal, empleo de significados originales, utilización de representaciones para elevar la capacidad del signo y el 
objeto, impacto reflexivo y las maneras de pensar cual usuario. A propósito de ellos se elaboraron como aspectos para colocar en la encuesta:

1. modo de representación,

2. frecuencia de uso,

3. lenguaje simbólico

4. semiótica social,

5. significación reflexivo-lingüística

6. conversación virtual

\subsection{Resultado de la encuesta}

Como resultados de la encuesta puede señalarse que constituyó un reto traducir los aspectos listados en interrogantes y lograr reacciones sustantivas, unas fueron más interpretables, pero en sentido general, se alcanzó comprensibilidad.

La impronta del documento generó textos donde visualizar los significados subyacentes de las respuestas y anotar observaciones para el análisis hermenéutico. En dichos textos se identificó que los discursos textuales ocupan una prioridad en la comunicación seguidos de los audiovisuales y los visuales. Asimismo, evidenciaron que la interacción con el medio de comunicación ocurre de manera formal e informal, la sinonimia, la abreviación de palabras, los autotraductores, emojins y emoticonos, las expresiones sentimentales y las ideas camufladas son los medios de comunicar su realidad.

Otro resultado de la encuesta se resume en que aspiran a dotar de comicidad la escritura, que a las palabras se le reducen los grafemas conservando los semas al máximo, que las aplicaciones de los teléfonos inteligentes (emojins, gifs, autocorrector), así como dibujos y códigos de la aplicación son maneras de expresar sus ideas. Además, que la mediación activa la sustentan en recursos lingüísticos inmediatos y dinámicos preferentemente, que las fuentes de originalidad de su discurso se localizan en la recreación primariamente y el estudio en segundo lugar. Que transforman el lenguaje para expresar intensidad de las ideas; así como, para expresar un nuevo sentido, con un limitado énfasis en la nueva cualidad al significado.

Finalmente, se pudo apreciar que en lo relacionado con el desarrollo del pensamiento mediante Wasap los encuestados no revelan una coincidencia en cuanto a que constituya una posibilidad para gestar nuevas lógicas y configuraciones significantes; para unos las trasformaciones lingüísticas no cambian el modo de pensar solo de expresión, se pierden 
valores y cultura al hablar, hay entorpecimiento ortográfico y pobre interés en la lectura, se distorsionan los mensajes para vivir en un mundo ficticio, es una razón de los problemas ortográficos y de redacción, se produce un alejamiento de la interacción física y hay olvido de las normas de la gramática.

Frente a esos criterios se observan otros que se sintetizan en amplitud y capacidad del pensamiento, innovaciones de sentido, placer y nuevos sentimientos al escribir, tendencias que se explican por una adaptación al nuevo mundo, las nuevas tecnologías y al hábito de ideas diarias en ellas. Esas razones las argumentan como causa para llegar a la realización de transferencias lingüísticas, nuevas maneras de expresar y capacidad para transformar palabras que son instaladas por el aprendizaje.

\subsection{Resultados del análisis hermenéutico}

La riqueza de argumentos obtenidos condujo a la realización de un análisis interpretativo que explorara los fundamentos que respaldan los comportamientos expresivos. En la construcción de las respuestas a una de las interrogantes de la encuesta, evidencia las siguientes variaciones lingüísticas: "compañeros, amigos o guambras", donde se configura la serie a partir de sustantivos; "te quiero, me conmoviste, estoy triste", conformada por construcciones morfosintácticas; "negritas, cursivas o subrayadas", una serie estructurada por marcadores discursivos, indicadores de la diferenciación entre modalidades de producción. Otro interpretante es "onta tas" que se construye para expresar: "dónde estás" a través de la elipsis de grafemas y dejar solo los sonidos que son base común del significado.

Los anteriores modos de representación, se apreciaron determinados por el contexto urbano, lo cual homogeniza los resultados; sin embargo, resultó paradójica esta idea porque algunos de ellos no eran de la ciudad, pero se presentaron como tales. Un hecho que explica la asimilación de una semiosfera urbana que inconscientemente va determinando los efectos en las culturas individuales. En sus respuestas se aprecian asimismo la estimación de emoticones, cuales símbolos que carecen de audio, pero con mucha comunicación. Este resultado evidencia la intencionalidad de la coherencia con la estructura global del significado. Existe un uso de lenguaje propio del contexto urbano actual y una estandarización de la cultura, generadora de diálogos virtuales como expresión precisa de las huellas del contexto.

Referido a la frecuencia de uso de la mediación activa de Wasap se obtuvo como resultado que los códigos son empleados de manera inmediata; es decir, al momento de escribir, mientras que los dinámicos se mostraron cuando se usa intencionalmente y los 
códigos finales, al concluir el mensaje. Constituyen los códigos inmediatos y dinámicos los más apelados en los mensajes. Esto representa la adopción de una postura interactiva frente a los códigos finales, lo que significa la posesión de una competencia lingüística.

En cuanto a las fuentes del lenguaje simbólico y la originalidad se aprecia que en la selección de significados novedosos y originales tienen localizados los ámbitos que constituyen vida cotidiana para los encuestados, quienes ven esas fuentes como realidad significativa. Lo cual se evidencia en las respuestas dada por ellos: que las actividades que constituyen fuentes del lenguaje son: la recreación, el estudio y el deporte.

La capacidad del signo, los encuestados la aprecian mediante el uso de emojins, destacando la intensidad del mismo como propósito de la utilización de Wasap unido a la intención de propiciar un sentido original en los mensajes mediante la búsqueda de nuevas cualidades al significado, posibilidad que facilita adoptar un estilo informal, caracterizado por la simplicidad sintáctica, el uso de novedosas reglas de tratamiento, un léxico más limitado y coloquial, y la presencia de préstamos del inglés. Hechos con los que aspiran a elevar la lexicalidad del signo.

Un análisis de los millennials ecuatorianos en Wasap conduce a valorar la medida en que dicha plataforma viabiliza el desarrollo del pensamiento en tanto medio de instalación de un conocimiento y lectura a la construcción del discurso desde las nuevas lógicas y configuraciones del significado y el significante. Tales elementos referidos a este ámbito proponen sean evaluados como hablantes convincentes debido a que la re-estructuración del discurso en base a la inserción de símbolos, la combinación de semas, la percepción de un receptor competente y la creatividad en la configuración del mensaje a partir de macroestructuras de significación permiten definir al productor de discursos como sujeto parcialmente productivo. Tal capacidad emerge en el acto metodológico de un debate epistémico (Walsh, 2017, p. 29) que tiene como argumento la aceptación de una intención renovadora del significado frente a una postura conservadora que se ilustra en el continuum "novedad-rapidez versus irrespeto ortográfico-gramatical".

Esa lucha epistemológica muestra el rol desempeñado por la enseñanza de la lengua en el escenario actual del Ecuador; evidencia la existencia de una práctica tradicionalista, conduce a una convicción acerca de la estabilidad en el lenguaje. Esa dimensión gnoseológica tiene como fundamento que el manejo de nociones teóricas conservadoras no facilita el aprendizaje de nuevos modos de analizar el texto. La polaridad en los comportamientos expresados por los estudiantes indica que existen conductas favorables a la configuración de 
textos donde la emergencia de novedosas formas significantes posibilita anclar su discurso en la realidad tecnológica donde el pensamiento es la brújula de las prácticas culturales y educacionales.

Los resultados alcanzados conducen a establecer desafíos para la educación superior de Ecuador, que requiere la adscripción a la pedagogía de reflexión y acción (Walsh, 2017, p.29) donde la emergencia de debates desplaza prácticas tradicionales en aras de facilitar diálogos emergentes (Alexander, 2005, p.7), una proyección pedagógica nacida en Ecuador desde la legitimidad de los contextos que se mueven en las diferentes zonas donde conviven las numerosas etnias que lo hacen un país pluricultural. La preeminencia de las imágenes es un universo de interpretantes que en la vida comunicativa del país conviene reforzar cual postura decolonizadora en el discurso de imaginarios como un continuum.

Los jóvenes demostraron como alcanzar con esta plataforma, posibilidades de mayor conocimiento y elevar su comunicación con pares, facilitar la creatividad que supone la interpretación de los signos al aportar índices, íconos y símbolos que facilitan las reglas de comprensión, es decir, el proceso de inferencias. Este nivel de pensamiento opera mediante procesos psicológicos para el procesamiento del texto actualizando sus macroestructuras, es decir, los atributos socioculturales y guiones que desempeñan en la interpretación.

La práctica discursiva, en la mensajería instantánea a través de Wasap y los significados que producen en su entorno social desplegaron dinámicas del lenguaje, sobre todo en este rango etario de 18 a 25 años, ya que los modos de representación de los interpretantes están determinados por el contexto con gran significatividad, propio del contexto actual, y, la estimación de emoticones en la comunicación soportada en la intencionalidad de la coherencia que según Van-Dijk (2006) opera en la estructura global del significado.

Los universitarios al adoptar una postura interactiva en una situación comunicativa entre dos personas mediada por Wasap, imponen a la educación superior una dinámica innovadora para conducir la producción de ideas y formas de retroalimentación.

La configuración de interpretantes se soporta en la búsqueda de fuentes de lenguaje simbólico y original; millennials universitarios integrantes de la muestra, la identificaron tanto en la cotidianeidad como en lexías que configuran la jerga o lenguaje local, constitutivo de un modelo de discurso de los jóvenes cuyas diferencias de género se soportan en que las féminas no emplean las insinuaciones emotivas con el desenfado de lo masculino, sin embargo, en el tema afectivo y de lo cotidiano tienden a semejarse lo cual emerge del principio de Peirce: "cualquier cosa que algo sea, es también un signo" (Peirce citado en Rodríguez-Martínez, 
Valerio-Ureña, Cárdenas-Anaya y Herrera-Murillo, 2016, p. 122). Es decir, los textos en la mensajería instantánea expresan un pensamiento representativo de un movimiento hacia la audacia en la interacción comunicativa donde se advierte una concepción pragmática del objeto. Elementos retadores para los procesos formativos universitarios.

Las reglas que orientan esos comportamientos muestran como las personas cuando realizaron sus reacciones significativas las efectuaron desde las comprensiones que le provocan las apelaciones del emisor, así ante preguntas dirigidas a conocer el modo de empleo de la renovación interpretativa explican:

- La fusión de textos e imágenes tiene como propósito reiterar mayor sensibilidad, es decir, acercar con signos el lenguaje escrito al oral mediante la reiteración de semas.

- La intención de comunicar algo nunca dicho se logra expresando ideas camufladas, nombre otorgado por ellos al doble sentido o metaforización;

- El reemplazo y síntesis significante busca lograr más precisión significativa utilizando preferentemente consonantes sin vocales;

- Los cambios lexicales utilizan procedimientos de variación sustentados en incitaciones a otros significados mediante la distinción de la identidad cultural.

- La brevedad se asume como gitfs, stickers emoticones y signo de ideas concretas.

Los casos descritos revelan la necesidad de una atención frecuente a series de interpretantes, una generación de interpretante en relación con un representamen que configura la semiosis infinita con la fundación de nuevos signos en el proceso de uso e interacción lo cual da lugar al enriquecimiento de la lengua, así como de los cambios lingüísticos por procesos de asimilación y mimesis en los procesos universitarios.

Esa lucha de conocimientos muestra el rol desempeñado por la enseñanza de la lengua en el escenario actual de las IES del Ecuador; evidencia de la emergencia de una convicción acerca del lenguaje. Esa dimensión gnoseológica tiene los fundamentos siguientes:

- El manejo de nociones teóricas genera un aprendizaje de texto.

- El habla expresa emociones y rapidez en las ideas.

- La relación tríadica en el interpretante modifica las ideas al aportar nuevos sentidos.

La dimensión gnoseológica referida conecta el pensamiento que se desarrolla con el concepto de semiosfera de luri Lotman: condición o espacio básico para el desarrollo de la cultura y las subculturas (o aloculturas) de un contexto dado. La cultura no es para Lotman, 
como se evidencia en sus escritos, un simple depósito o una mera suma de informaciones, agrupadas sin orden; al contrario, se puede definir la cultura como mecanismo generador de la visión que del mundo se tiene. En la cultura, como sistema modelizador secundario, la lengua natural constituye la base sobre la que se alzan sistemas de signos antropológicos, filosóficos, literarios o políticos.

Sobre esta base y tomando en cuenta variantes léxicas, el equipo docente debe incorporarlas en el proceso de confección del plan a ser utilizado para la interacción profesorado-estudiantado a través de Wasap en la enseñanza de una segunda lengua. El concepto que sobre "cultura" ofrece Williams servirá para poder analizar el modo en que las prácticas culturales son reflejadas en la e-educación por Wasap dado su carácter de aparente realidad contextual que contribuye activamente a las elaboraciones referidas.

La realidad contextual conduce a los entornos que configuran las estructuras de sentimientos en la definición de cultura. Vertientes diferentes que al ser tenidas en cuenta en la elaboración de argumentos dentro de los planes de clases a ser expuestos al estudiantado le incita a la manipulación de categorías como son:

- Categorías generales en la definición de cultura. El análisis de la cultura, si se acepta esta definición, es esencialmente el descubrimiento y la descripción en vidas y trabajos de aquellos valores que componen un orden sin tiempo, o puede ser la referencia permanente o la condición humana universal.

- La cultura es el cuerpo del trabajo intelectual e imaginativo, en el cual, de un modo detallado, tanto la experiencia como la conciencia humana, son registradas de varias formas. El análisis de la cultura desde esta definición es la actividad del criticismo, por lo cual la naturaleza del pensamiento y de la experiencia, los detalles del lenguaje, la forma y convención en que estos se activan, son descritos como valores.

- Finalmente, la definición social de cultura, en la cual se concibe como una descripción de un modo particular de vida, el cual expresa ciertos significados y valores, no solo en arte y aprendizaje y, además en las instituciones y el comportamiento común u ordinario. Su análisis desde esta perspectiva, es una determinación de los significados y valores implícitos y explícitos en un modo particular de vida.

Toda cultura es básicamente pluricultural, es decir, se ha ido formando y se sigue formando, a partir de los contactos entre distintas comunidades de vidas que aportan sus modos de pensar, sentir y actuar. Desde esta perspectiva, la representación pedagógica del 
maestro es una delegación de las actividades de interacción que se deben efectuar en el proceso docente educativo en ciertas formas de comunicación, en este caso, se hace referencia a la modalidad Wasap de las redes sociales.

Los fenómenos y estructuras sociales serán la base de los procesos a desarrollar en el empleo de Wasap para la e-educación. Es condición que el profesorado conozca de las características socio-contextuales en las que se desarrolla el estudiantado para poder establecer los códigos de comunicación que generarán nuevos interpretantes, siempre a partir de aquellos códigos que ya han sido preestablecidos por los usuarios de las redes.

\section{Conclusiones}

La sociolingüística presentada en este trabajo muestra que la práctica es reveladora de variaciones lingüísticas producto a la globalización y a las tecnologías de información; han modificado las explicaciones de los atributos sociales y dan mayor relevancia a factores sociológicos como los contextuales significativos; resultan realidades que permiten fundamentar una relación directa entre tales variables y las maneras de expresión; la nueva realidad global pone en cuestionamiento las posturas teóricas que explican de una manera absoluta los fundamentos socioculturales en los comportamientos discursivos del estudiantado y las variaciones que producen en su lenguaje.

La semiosis infinita replantea las relaciones del signo con su objeto e interpretante en escenarios multitareas que los nativos digitales deben desempeñar para validar las ideas de Eco (1999) sobre "la circularidad como condición normal para el proceso de significación" (p. 118). El estudio demuestra que dicha semiosis se caracteriza por el empleo de interpretantes soportados en lenguaje simbólico y original tanto en la cotidianeidad como en lexías que configuran la jerga y constitutivo de un modelo de discurso de los jóvenes.

Los interpretantes se orientan por reglas dirigidas a una renovación caracterizada por la fusión de textos e imágenes que reiteran mayor sensibilidad mediante el acercamiento del lenguaje escrito al oral, expresando ideas camufladas, el reemplazo y síntesis significante preferentemente de consonantes sin vocales, cambios lexicales a través de incitaciones a otros significados y la brevedad mediante gitfs, stickers y/o emoticones, cual signos de ideas concretas.

Las variaciones vistas construyen series de interpretantes a partir de sustantivos, símbolos visuales, construcciones morfosintácticas y el uso de marcadores discursivos empleados como modalidades de producción; resultó interesante el acercamiento de palabras 
a los sonidos mediante la elipsis de fonemas. Estas categorías resultan las de mayor novedad y riqueza semántica donde la semiosis infinita de interpretante en interacción con el representamen da lugar al enriquecimiento de la lengua, así como, a cambios lingüísticos por procesos de asimilación y mimesis.

Los hechos estudiados demuestran la urgencia de otro método para el análisis discursivo y otro docente. Como se demuestra ante las diversas perspectivas metodológicas para la enseñanza de una lengua extranjera, posibles desde las redes virtuales y específicamente a través de la aplicación Wasap. Las metódicas más eficaces son las basadas en la sociolingüística.

La clase de lenguaje hoy demanda un enfoque sociolingüístico mediante la colocación del estudiantado en un continuum donde la reflexión sobre el discurso se polarice entre interpretantes y representamen, categorías significativas y significantes explicadas por la estructura social y la estabilidad de un determinado significado, aspiración que genera una riqueza de pensamiento. Constituye un desafío que puede instalarse en clases productivas donde el estudiantado establezca hipótesis e interpretaciones en las cuales la sociedad actual sea una utilidad para la enseñanza.

La educación superior ecuatoriana como fenómeno social revela la problemática que representa para el profesorado la necesidad de conocer las características sociocontextuales, profesionalizante y lingüística para el empleo formativo de la mensajería instantánea en wasap.

\section{Referencias}

Acero, Juan José, Bustos, Eduardo y Quesada, Daniel. (2001). Introducción a la filosofía del lenguaje (5a. ed.). Madrid, España: Ediciones Cátedra.

Alexander, Jeffrey. (2005). Pedagogies of croussing. Meditations on Feminism, Sexual Politics, Memory and the Sacred. Durham: Duke University Press.

Andújar-Vaca, Alberto y Cruz-Martínez, María-Soledad. (2017). Mensajería instantánea móvil: Whatsapp y su potencial para desarrollar las destrezas orales. Revista Científica de Educomunicación, 25(50), 43-52. DOI: https://doi.org/10.3916/C50-2017-04

Blas, José Luis. (1994). Los pronombres de tratamiento y la cortesía. Revista de Filología, (13), 7-35. https://repositorio.uam.es/bitstream/handle/10486/668876/dialnet.unirioja.es/descarga/a rticulo/91834.pdf 
Bühler, Karl. (1934). Sprachtheorie Die Darstellungsfunktion der Sprache (traducido por Julian Marías: Teoría del lenguaje). Jena: Fischer.

Calderón, Miguel. y Medina, Francisca. (2010). Historia y situación actual de los pronombres de tratamiento en el español peninsular. En Betina Kluge Martin Hummel y María Eugenia Vázquez (Eds.), Formas y fórmulas de tratamiento en el mundo hispánico (pp. 195-222). México: Universidad de Graz: El Colegio de México.

Carricaburro, Norma. (1997). Las fórmulas de tratamiento en español actual. Madrid: Arco/Libros.

Castañares, Wenceslao. (1962). Algunas consecuencias de dos principios peirceanos. Universidad Complutense de Madrid. Signa, (1), 135-142. Recuperado de http://www.cervantesvirtual.com/servlet/SirveObras/06929511933558539732268/p0000 $\underline{003 . h t m \# 9}$

Charaudeau, Patrick. (2009). Reflexiones para el análisis del discurso populista. Discurso y Sociedad, 3(2), 253-279.

Eco, Umberto. (1991). Tratado de semiótica general. Barcelona, España: Editorial Lumen S.A.

Eco, Umberto. (1999). La estructura ausente. Introducción a la Semiótica. Barcelona, España: Editorial Lumens S.A.

Everaert-Desmedt, Nicole. (2004). Peirce's Semiotics. Recuperado de http://www.signosemio.com/peirce/semiotics.asp

Fondevila Gascón, Joan Francesc., Cabreras Alacalde, Marta., Mir Bernal, Pedro., Del Olmo Arriaga, Josep Lluís. y Pesqueira Zamora, María Jesús. (2014). El impacto de la mensajería instantánea en los estudiantes en forma de estrés y ansiedad para el aprendizaje: Análisis empírico. Revista Didáctica, Innovación y Multimedia (DIM), 10(30). Recuperado https://ddd.uab.cat/record/131898

Frápolli, María José. y Romero, Esther. (2007). Una aproximación a la Filosofía del Lenguaje. Madrid, España: Editorial Síntesis, S. A.

Fontanella de Weinberg, María Beatriz. (1999). Sistemas pronominales de tratamiento usados en el mundo hispánico. En Ignacio Bosque y Violeta Demonte (Eds.), Gramática descriptiva de la lengua española (pp. 1399-1426). Madrid: Espasa-Calpe.

Gómez Castells, Máximo Ricardo, Venegas Álvarez, Gina Silvana y Mena Vargas, Nelly Patricia. (2020, abril). La mensajería en WhatsApp y los interpretantes, ámbitos de pautas culturales y variaciones de la sociolingüística en millennials ecuatorianos universitarios de Cotopaxi. Presentado en Ponencia presentada en el Congreso de Sociología Alas- Perú, Lima, Perú.

Guerrero Ramos, Gloria. (1995). Nota La Lingüística del texto y la Pragmática Lingüística. Universidad de Málaga. E.L.U.A., 10, 443-446. 
Halliday, Mak. (1978). El lenguaje como semiótica social. La interpretación social del lenguaje y del significado. México: Fondo de Cultura Económica.

Hernández Sampieri, Roberto., Fernández Collado, Carlos. y Baptista Lucio, María del Pilar. (2014). Metodología de la Investigación (6a. ed.). México D.F.: Mc Graw Hill Education / INTERAMERICANA EDITORES, S.A. DE C.V.

Jakobson, Román. (1963). Ensayos de lingüística general. París: Minuit.

Jasper, James. (2012). ¿De la estructura a la acción social? La teoría de los movimientos sociales después de los grandes paradigmas. Sociológica, 27(75).

Jay, Meg. (2016). La Década Decisiva. Madrid: Ediciones Palabra. Recuperado de https://books.google.co.cr/books?id=Gi-

CDQAAQBAJ\&printsec=frontcover\&dq $=\mathrm{La}+\mathrm{D} \% \mathrm{C3} \% A 9$ cada+Decisiva\&hl=es\&sa=X\&ve d=2ahUKEwi8yNvl-

tLsAhUHo1kKHTBUC1wQ6AEwAHoECAIQAg\#v=onepage\&q\&f=false

Labov, William. (1983). Modelos sociolingüísticos. Madrid, España: Ediciones Cátedra S. A.

Ley de la juventud. N2001-49. (2001). Recuperado de https://www.acnur.org/fileadmin/Documentos/BDL/2008/6609.pdf

LLamas Saíz, Carmen. (2005). Discurso oral y discurso escrito: Una propuesta para enseñar sus peculiaridades lingüísticas en el aula de ELE. Universidad de Navarra, España: Actas del XI Congreso Internacional de ÁSELE.

Moreno de Alba, José. (1992). Anglicismos léxicos en España y América. Diferencias léxicas entre España y América. Madrid, España: Mampfre.

Moreno, Francisco. (2005). Principios de sociolingüística y sociología del lenguaje (2da. Edición). Barcelona, España: Editorial Erial.

Olivares Granados, Sergio Agustín y González Reyes, Janoé Antonio. (2016). Los retos de la docencia ante las nuevas características de los estudiantes universitarios. México, Nayarit: Proceedings-CECORFAN.

Padrón, Carmen Janeth. (2013). Estrategias didácticas basadas en aplicaciones de mensajería instantánea Whatsapp exclusivamente para móviles (Mobile Learning) y el uso de la herramienta para promover el aprendizaje colaborativo. Revista de Tecnología de Información y Comunicación en Educación, 7(2), 123-134.

Pierce, Charles Sanders. (1977). Semiotics and Significs: Correspondence Between Charles S. Peirce and Lady Victoria Welby. En Charles Hardwick (ed.), Bloomington. EE.UU: Indiana University Press.

Peñalosa Otero, Mónica Eugenia. y López Celis, Diana María. (2016). La generación de los millennials frente al consumo socialmente responsable. Cuadernos Latinoamericanos de Administración, 12(23), 73-81. 
Perelman, Chaim., Sevilla, Julia. y Olbrechts-Tyteca, Lucie. (1989). Tratado de la argumentación, la nueva retórica. España: Gredos.

Popescu, Diana., Popa, Diana Mariana. y Cotet, Beatrice Gabriela. (2019). Getting ready for Generation Z students-Considerations on 3D printing curriculum. Propósitos $y$ Representaciones, 7(2), 240-268. doi: http://dx.doi.org/10.20511/pyr2019.v7n2.280

Rigatuso, Elizabeth. (10 de junio de 2014). Cuestiones de variación lingüística en un sistema de tratamientos del español de la Argentina. El español bonaerense 1: extensiones metafóricas de términos de parentesco filiales. Boletín de la Academia Argentina de Letras, 79, 331-332.

Rodríguez-Martínez, M. Carmen., Valerio-Ureña, Gabriel., Cárdenas-Anaya, Carlos A. y Herrera-Murillo, Dagoberto J. (2016). Percepción y realidad del uso de WhatsApp en estudiantes universitarios de ciencias de la salud. FEM, 19(3), 119-124.

Schlieben-Lange, Brigitte. (1975). Pragmática lingüística. Madrid, España: Gredos.

Silvestre, Emmanuel y Cruz, Oliver. (2016). Conociendo la próxima generación de estudiantes universitarios dominicanos a través de las redes sociales. Ciencia y Sociedad, 41(3), 475-503.

Sinner, Carsten y Tabares Plasencia, Encarnación. (2016). El problema de las variantes fraseológicas desde la perspectiva de la lingüística de variedades. RLA. Revista de Lingüística Teórica y Aplicada, 54(2), 13-41.

Strauss, Anselm y Corbin, Juliet. (2002). Bases de la investigación cualitativa. Técnicas y procedimientos para desarrollar la teoría fundamentada (Primera edición (en español)). Colombia: Editorial Universidad de Antioquia.

Suárez Lantarón, Belén. (2018a). Whatsapp: Su uso educativo, ventajas y desventajas. Revista de Investigación en Educación, 16(2), 121-135.

Suárez Lantarón, Belén. (2018b). Whatsapp: Su uso educativo, ventajas y desventajas. Revista de Investigación en Educación, 16(2), 121-135.

Trejos Buriticá, Omar Iván. (2018). WhatsApp como herramienta de apoyo al proceso de enseñanza y aprendizaje de la programación de computadores. Educación y Ciudad, (35), 149-158.

Van Dijk, Teun. (2006). De la gramática del texto al análisis del discurso. Barcelona, España: Universidad Pompeu Fabra.

Venegas-Álvarez, Gina Silvana. y Proaño-Rodríguez, Carlos Enrique. (2019). Análisis sociolingüístico de la práctica discursiva a través de WhatsApp en millennials. Revista Científica Dominio de la Ciencias, 5(2), 304-327. https://doi.org/DOI: http://dx.doi.org/10.23857/dc.v5i2.1095 
Villalba, Cristina. y Kern, Beate. (2017). Apelación y atenuación: comparación intergenérica entre juicios orales y debates parlamentarios españoles. RLA. Revista de lingüística teórica y aplicada, 55(2), 169-195. doi: https://dx.doi.org/10.4067/S0718$\underline{48832017000200169}$

Voloshinov, Valentin Nikólaievich. (2009). El marxismo y la filosof'ia del lenguaje. Buenos Aires: Ediciones Godot Argentina.

Walsh, Catherine. (2017). Pedagogías decoloniales: Prácticas insurgentes de resistir, (re)existir y (re)vivir. Quito-Ecuador: Ediciones Abya-Yala. 
Revista indizada en

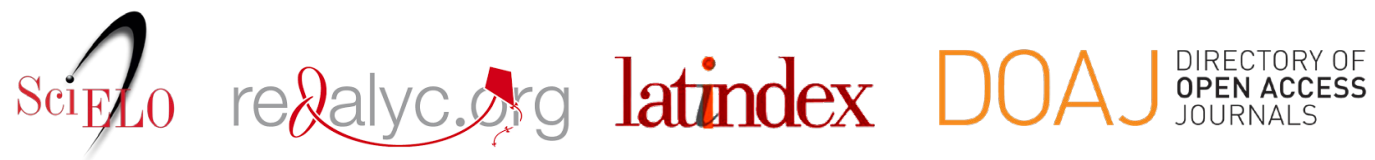

Distribuida en las bases de datos:

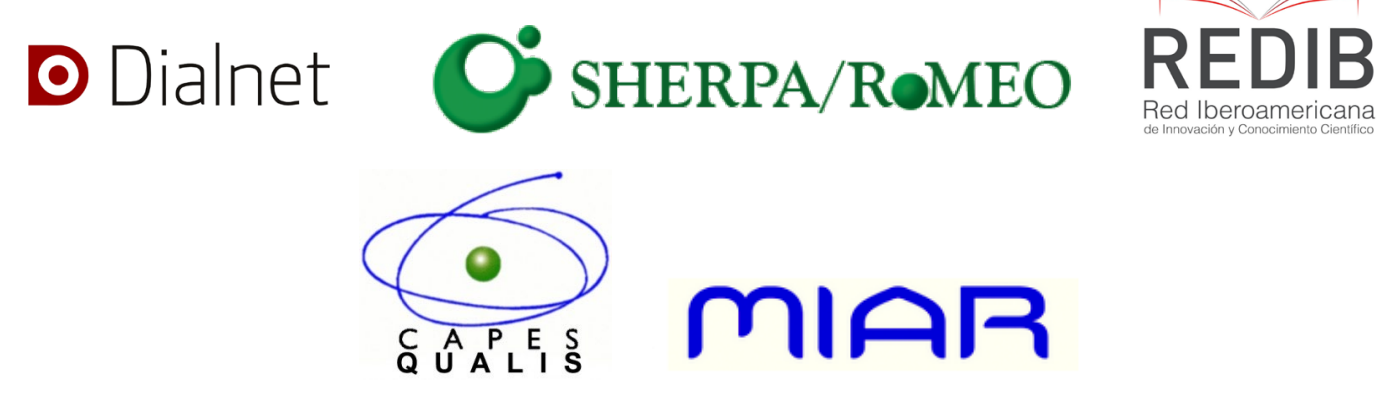

